\title{
Die böse Sieben
}

VON

\section{O. FRANKFURTER.}

Man hat verschiedentlich den ausdruck die sböse Sieben" für eine frau zu erklären gesucht, obne dass es mir bekannt wäre, dass eine dieser erklärungen auf inigemeinen beifall hat rechnen könnon. Es dürfte so vielleicht entschuldigt werden, wenn aus dem fernen Osten ein neuer versuch gemacht wird. Ess wird dabei gehofft dass sclbst wenn das, was im nachfolgenden zur erklärung vorgetragen wird, keine zustimmung findet, obwol es nur eine bestätigung von Professor Benfey's, im Pańchatantra ausgesprochenen hypothese, dass wir zur erklïrung für vieles in unserem volksleben in sagen und gebräuchen auf den Butlhismus zuräckgreifen müssen, wïre, die vorgebrachteu tatsachen vou geuügendem interesse sind um deren veröffentlichung zu rechtfertigen.

Das in Birma gauz und gäbe gesetz unterscheidet sieben arten von franen, nemlich die frau wie eine mutter, wie eine schwester, wie ein freund, wie ein sklave, wie ein herr, wie ein feind und wie ein dieb. Das gesetz schreibt vor dass weun es bewiesen ist dass eine fran, wie ein feind oder wie ein dieb an ihrem manne gehandelt hat, sie als solche bestraft werden sollte, und an einer anderen stelle, dass selbst wonn kinder der ebe entstammen, der 
mann sich von einer frau, die wie ein herr, ein feind oder ein dieb gegen ihn gehandelt hat, scheiden lassen kaun.

Es ist schon früher darauf hingewiesen, so namentlich von Forchhammer, dass, obwol das gesetz, wie es in den von Buddhisten bewohnten ländern Hinterindiens üblich ist, im grossen und ganzen auf brahmanischer grundlage beruht, und zwar auf den gesetzbüchern die unter den namen des Mam gehen, doch die Buddhistischen schriften einen merkliehen einfluss auf die gesetzgebung der einzelnen lünder ausgeübt habeu. Es ist solcher einfluss nicht immer direct und namentlich uicht immer zeitlich nachweisbar, da die gesetzgeber, auf alter grundlage weiterbauend, ihre individuelle anschauung derselben anfzudrücken suchten, ohne dass es ihuen daran lag diese neue gesetzgebung mit ihrem namen zu verknüpfeu.

So finden wir denu das, was bei dem einem rolke, den Birmaneu, in das gesetz übergegangen, bei einem andern volke, den Siamesen, in die volkslitteratur ïbergegangen ist. Dies geschah wol zuerst als rechtssprichwort, wie sich das auch sonst nachweisen lïsst, so beispielshalber mit dem bekannten siamesischen sprichwort »beisst dich der hund, so beiss ihn niclst wieder", das anf buddhistischer grundlage beruht, und das im birmanischen gesetz über mord als argument gegen die anweulung der lex talionis gebraucht wird.

Die Siamesische volkslitteratur unterscheidet ebenfalls sicben arten von frauen, doch werden von ihrer individualität keine rückschlüsse auf das, dem manne wach dem gesetze zustehende, recht gemacht.

Wir finden, mit schlechten eigenschaften beginnend, die folgende reihe: eine frau wio ein mörder, wie ein dieb, wie ein meister, wie ein freund, wie eine jüngere schwester, wie eine ältere schwester, wie eine mutter. - Die Siamesischen namen für diese kategorien sind durchweg tem Pāli, aller wahrscheinlichkeit nach durch Canibodianische quellen, evtlchnt, da wir auch sonst in der beschreibung 
dieser sieben eine unverhältnismässig grosse anzahl wörter Cambodianischen ursprungs finden.

Die frau wie ein mörder $»$ vadhakā bhiriyă" wird beschrieben wie eine die, einem henker gleich, dcm leben ihres mannes nachstellt. Sie ist von niedriger herkunft; elebrecherisch und wollüstig, erkennt und sucht sie nur nach fehlern und den schlechten seiten ihres eleherrn, den sie, wenn gelegenheit sich böte, selbst töten würde.

Die frau wie ein dieb »cori satrī" wird beschrieben als eine, die nicht auf das vermögren ihres mannes acht gibt, sondern es im spiel mit andern vertändelt, und ibn zum bettler macht. Sie ist lügnerisch und ohne furcht ror ilırem manne.

Die frau wie ein meister »ayya bhiriya" sucht ihren eignen willen dem des mannes entgegenzusetzen; sie behandelt ihren mann als weun sie der meister, er der sklave, sie der herr, er der knecht sei.

Die frau wie ein freund sakhĩ bhiriyä" behaudelt ihreu mann als weun er ihr freund wäre; von gehorcheu kamn nicht die rede sein, da sie eben nur das tut, was ein freund dem andern zu liebe tun würde, so lauge es ihr passt.

Die frau wie eine jüngere schwester »kanishṭha bhiriya" sieht zu ihrem maune auf wie die jüngere schwester zum bruler; sie gehorcht ihm, sorgt für ihn nnd für seine elre, sie ist geduldig.

Die frau wie eine ältere schwester »jèshṭhaka bhiriga" sieht darauf wie sie sich frei von fehlern halten kaun; bescheidentlich wirtet sie ihren manne auf; selbst in ihrem anzuge weiss sie das was anständig ist zu tragen und zu bewahren; wie eine ältcre schwester einer jüngcren gegenüber, nimmt sie auf sich die ehre ihres mannes zu schützen: sic bült von ihın die sorge des täglichen lebens fern und sucht ihn dazu zu bestimmen, dass er nur das tut was gerechtigkeit erfordert.

Die frau wie eine mutter »matā bhiriya": Wie eine mutter ihr 
kind liebt, so liebt die frau wie eine mutter ihren eheherrn; sie weist ihn an das zu tun, was recht und gut ist; sie wird für ihn wirken und schaffen; ihn, wenn er krank ist, pflegen wie eine mutter nur ihren liebling pflegen kann.

Nun wird in der Siamesischen poetischen version (laksana mia chek sthan), von der wir eben eine sinngetreue übersetzung gegeben, berichtet das sie wiederun dem Satanipāta des Ariguttaranikāya entnommen sei. Wir finden so denn auch im Sujāta sutta eine aufzählung der sieben arten frauen und zwar als vadhasamā gleich einem mörder, corasama $\bar{a}$ gleich einem dieb, ayyasamā gleich einem meister, mätusama gleich einer mutter, bhagin $\bar{s} \operatorname{sim} \vec{a}$ grleich einer schwester, sakhīsamā gleich einem freunde, dāss samā gleich einer sklavin.

Dieser selben auffassung von den sieben frauen begegnen wir in deu bildlichen darstellungen in den vorhöfen der Siamesischen tempel. In diesen werden als gut betrachtet, die frau wie eine freundin, wie eine mutter, wie eine schwester und wie eine sklavin, während die poetische version als gut nur die frau wie eine mutter und wie eine ältere und jüngere schwester nennt, wo ja wol unter fremdem Cambodianischen einfluss die jüugere schwester für die sklavin substituiert ist. - Das Pāli stimmt somit ferner ïberein mit der im Birmanischen gesetz gegebenen version, und so haben wir natürlich das Sujāta sutta als quelle des ganzen zu betrachten. In der Siamesischen version wird einfach die tatsache berichtet, das die sieben arten frauen existieren; im Birmanischen werden rückschlüsse auf das gesetz gemacht, wïhrend das Sujāta sutta als grundlage des ganzen, auf religiöser gruudlage beruhend, die taten (kcrmma) begangen als frau wie eine mörderin, ein dieb, ein meister in der hölle weiter leben lässt, wo sie natürlich das in der hölle bereits 
bestehende böse kamma vermehren; wïhrend die taten begangen als frau wie eine mutter, schwester, freundin, sklavin in den seligen gefilden des himmels das gute kamma vermehren. Es kann eben nicht häufig geung darauf aufmerksam gemacht werden, das von einem körperlichen fortleben im reinen Buddhismus nicht die rede sein kann, sondern nur von dem fortleben der taten. 